\title{
New Objective Criteria for Inflammation in Bronchial Secretions*
}

\author{
H. BÜRGI, M.D., U. WIESMANN, M.D. ; R. RICHTERICH, M.D., ; J. REGLI, M.D. ; T. MEDICI, M.D.
}

Brit. med.F., 1968, 2, 654-656

Objective criteria for the evaluation of improvement or aggravation of chronic bacterial infection of the bronchial tree are lacking. For the evaluation of the effect of chemotherapeutic or antibiotic treatment in chronic bronchitis a wide variety of criteria are used. These range from objective bacteriological examination-sometimes by unsuitable methods -to insignificant remarks concerning cough, respiratory difficulties, and expectoration, which depend to some degree on the co-operation and understanding of the patient. The improvement in pulmonary function, as measured by standard techniques, and the frequency of clinical relapse are often used as criteria in the assessment of response to therapy. But any one of these criteria, helpful as each may be in those patients whose pathological lesions are reversible, is nevertheless a secondary feature and depends on remission of the infective process.

To rely solely on bacteriological methods as a measure of therapeutic effect can of ten prove valueless and unsatisfactory, though with improved techniques-for example, that of

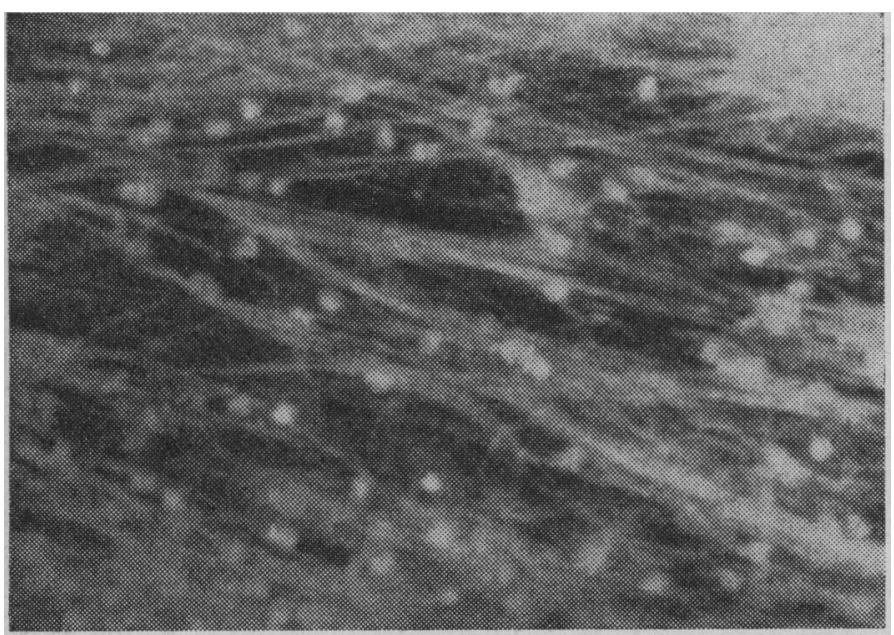

FIG. 1.-D.N.A. fibres in an inflammatory secretion shown by fluorescence microscopy.

Rawlins (1953)-bronchopathogenic organisms were found in 97\% of all patients with chronic bronchitis, irrespective of the clinical state (Medici and Bürgi, 1965). Further extensive observations (Bürgi, Regli, and Medici, 1965) have shown that the mere presence of certain organisms in the bronchi is not necessarily indicative of a pathological process. Quite often, even in the presence of known pathogenic bacteria, no evidence of inflammation-namely, cell destruction or accelerated mitoses -could be demonstrated in the bronchial secretions.

Previous papers have already shown that fluorescent microscopical techniques can be used to demonstrate that inflammatory bronchial secretions are composed of tightly intertwined fibre layers of deoxyribonucleic acid (D.N.A.) (Bürgi, Regli, and Wiesmann, 1966 ; Bruce and Kumar, 1967). The appearance of D.N.A. fibres found in an inflammatory exudate under conditions of fluorescent microscopy is shown in Fig. 1. The present paper is concerned with the changes in the levels of

- Bernische Heilstätte Heiligenschwendi, Department of Paediatrics, University of Berne, and Central Chemistry Laboratory, Inselspital, Berne, Switzeriand.
D.N.A. and lactic dehydrogenase (L.D.H.) and its isoenzymes in both inflammatory and non-inflammatory bronchial secretions from patients with chronic bronchitis.

\section{Materials and Methods}

Patients who had already been under medical care for several months provided serial samples of sputum for bacteriological and biochemical examination. Only sputum expectorated from the depths of the bronchial tree was examined. Evidence of bronchial infection was based on bacteriological examination of the sputum together with its biochemical analysis as well as a clinical assessment of the patient. In addition, alterations in the bacteriology and the biochemical concentrations of D.N.A., L.D.H., and L.D.H. isoenzymes were observed during antibiotic therapy. The results of the bacteriological findings and clinical assessments are compared with the biochemical data.

Bacteriological examinations followed the method described by Rawlins (1953). D.N.A. was determined spectrophotometrically with a Zeiss PMQ II spectrophotometer after it had been isolated by a procedure described by Schmidt and Thannhauser (Volkin and Cohn, 1954). The L.D.H. activity of sputum was measured with the spectrophotometer on a homogenized specimen of sputum containing pyruvate substrate. The following items were used to make pyruvate substrate: pyruvate $0.86 \mathrm{mM}$, hydrous nicotinamide-adenine dinucleotide $428 \mathrm{mM}$, triethanolamine buffer $50 \mathrm{mM}, \mathrm{pH} 7.5$, and edetic acid $5 \mathrm{mM}$. The determinations of L.D.H. were performed in semimicrocuvettes thermostatically controlled at $25^{\circ} \mathrm{C}$. in an Eppendorf photometer fitted with a linear $W+W$ recorder to determine the extinction point.

The results are expressed in micromoles of substrate per litre, and in milligrams per gramme of sputum for L.D.H. activity and D.N.A. concentration respectively. Separation of the L.D.H. isoenzymes was performed by agar-gel electrophoresis on glass slides ( 26 by $76 \mathrm{~mm}$.), using barbiturate buffer with an ionic strength of 0.1 at $p H$ 8.4. Each slide was subjected to a current of $20 \mathrm{~mA}$ for 40 minutes. The staining method requiring tetrazolium and phenazin methosulphate was used to identify the L.D.H. fractions (Wieme, 1959).

\section{Results}

Sputum samples obtained from patients with inflammatory bronchial lesions have high values of D.N.A., ranging from 2.9 to $8.7 \mathrm{mg}$. $/ \mathrm{ml}$. of sputum ; the mean value in these patients was 5.2. In the absence of an inflammatory process the D.N.A. levels ranged from 0 to $2.95 \mathrm{mg} . / \mathrm{ml}$. of sputum. The levels of D.N.A. found in the sputum samples are shown in Table I. L.D.H. activity in bronchial secretions was found to vary widely. Nevertheless, there was a significantly larger amount of L.D.H. in infected sputum as compared with samples from uninfected patients. However, there was some overlap between these two categories. It was found that in inflammatory secretions the L.D.H. activity is mainly represented by isoenzyme fractions 4 and 5 , whereas in non-inflammatory sputum L.D.H. is either practically absent or confined chiefly to fractions $1-3$. 
TABLE I.-L.D.H. Activity and D.N.A. Content (the Mean \pm Twice the Standard Deviation are Shown) in Bronchial Secretions of Patients With Chronic Bronchitis With and Without Inflammatory Processes. The Presence of an Inflammatory Process in the Bronchial Tree was Established by Positive Bacterial Culture, Clinical Investigation, and High D.N.A. Fibre Content $(++,+++)$ in Fluorescence Microscopy

\begin{tabular}{|c|c|c|c|c|}
\hline $\begin{array}{l}\text { Inflammatory } \\
\text { Process }\end{array}$ & $\mathbf{N}$ & $\begin{array}{l}\text { D.N.A. } \\
\text { (mg./mi. sputum) }\end{array}$ & $\begin{array}{l}\text { L.D.H. } \\
\text { (I.U./I. sputum) }\end{array}$ & $\begin{array}{l}\text { L.D.H. isoen- } \\
\text { zyme Fractions }\end{array}$ \\
\hline $\begin{array}{l}\text { Present } \\
\text { Absent }\end{array}$ & $\begin{array}{l}10 \\
10\end{array}$ & $\begin{array}{l}5 \cdot 2 \pm 2 \cdot 1 \\
(2 \cdot 9-8 \cdot 7) \\
1 \cdot 1 \pm 0 \cdot 8 \\
(0-2 \cdot 95)\end{array}$ & $\begin{array}{c}1,802 \pm 901 \\
(479-3,700) \\
168 \pm 140 \\
(1-479)\end{array}$ & $\begin{array}{c}4 \text { and } 5 \\
1-3\end{array}$ \\
\hline
\end{tabular}

In order to compare the amount of D.N.A. as shown by fluorescent microscopy and D.N.A. concentration as determined by chemical means, each sputum sample was initially examined by fluorescent microscopy and placed into one of three groups according to its content of D.N.A. fibres. Each group contained 50 samples. The results of the D.N.A. concentration and L.D.H. activity in all the samples are shown in Table II. Though there is some overlap in L.D.H. activity

TABLE II.-Correlation Between D.N.A. Fibres in Fluorescence Microscopy and D.N.A. Concentration and L.D.H. Activity (the Mean 士 Twice the Standard deviation are Shown) in Sputum

\begin{tabular}{c|c|c|c}
\multicolumn{2}{c}{ Twice the Standard deviation are Shown) in Sputum } \\
\hline $\begin{array}{c}\text { No. of } \\
\text { Patients }\end{array}$ & $\begin{array}{c}\text { D.N.A. } \\
\text { Fibres }\end{array}$ & $\begin{array}{c}\text { D.N.A. } \\
\text { (mg./mi. sputum) }\end{array}$ & $\begin{array}{c}\text { L.D.H. } \\
\text { (I.U./1. sputum) }\end{array}$ \\
\hline 10 & 0 & $1 \cdot 1 \pm 0.80(0-2 \cdot 95)$ & $168 \pm 140(1-479)$ \\
50 & + & $2 \cdot 7 \pm 0.65(0 \cdot 8-3 \cdot 5)$ & $256 \pm 58(98-352)$ \\
50 & ++ & $3 \cdot 2 \pm 2 \cdot 2(0 \cdot 6-10 \cdot 7)$ & $462 \pm 118(210-657)$ \\
50 & +++ & $9 \cdot 9 \pm 2 \cdot 2(4 \cdot 4-14 \cdot 7)$ & $984 \pm 304(441-1,537)$ \\
\hline
\end{tabular}

+ Small number of D.N.A. fibres present.

++ Intermediate number of D.N.A. fibres present.

+++ Large number of D.N.A. fibres present.

between the three groups, nevertheless a highly significant difference is found between the two groups with high and low D.N.A. concentrations.

\section{Clinical Application in Antibiotic Trials}

In order to assess the value of the biochemical examination of sputum as one criterion of the success of the use of an antibiotic, the L.D.H. activity and D.N.A. concentrations were estimated in the sputum of patients while receiving antibiotic therapy. Ten patients with clinical and bacteriological evidence of bronchial infection received 14 days' treatment with ampicillin $1 \mathrm{~g}$. daily; the morning secretions from each patient were examined (Fig. 2). Haemophilus influenzae was found in all the sputa. There was a decrease in sputum L.D.H. activity in all but one of the patients. The D.N.A. concentration also fell, but not quite as rapidly as the L.D.H. activity, and both levels remained low until the end of the period of treatment. There was no clinical relapse in any of the patients. The variation of D.N.A. and L.D.H. levels in sputum containing $H$. influenzae together with the clinical findings suggest that the mere presence of this organism in sputum is not sufficient proof of an inflammatory process (Fig. 2).

Similarly, the estimation of D.N.A. concentration and L.D.H activity in sputum can be used to detect the failure of antibiotic response. This was demonstrated in six other patients with chronic bronchial infections due to the pneumococcus, Neisseria catarrhalis, and streptococci. These six patients were treated with a broad-spectrum antibiotic, and the L.D.H. and D.N.A. sputum levels were estimated in morning and evening samples, obtained after intensive physiotherapy (Fig. 3). In all six cases the L.D.H. activity and D.N.A. concentration had fallen within 24 hours, even including those patients whose initial level had been within the normal range. After 36 hours of treatment an increase in L.D.H. activity was observed in all patients, which was interpreted as a return of the infection. The first clinical evidence of relapse became obvious in one of the patients by the fourth day. Subsequently all the remaining patients relapsed with clinical signs of infection and mucopurulent sputum. At this point bacteriological examination of the sputum showed that each one of the original organisms had developed resistance to the particular antibiotic being administered.

\section{Discussion of the Biochemical Criteria}

The D.N.A. which can be demonstrated either by fluorescent microscopy or by quantitative determination in the bronchial secretions probably originates both from the nuclei of disintegrated inflammatory cells and the destruction of the bronchial mucosal cells. The levels of D.N.A. in infected secretions are high and are a reflection of destruction of a large amount of cellular material. The results of our estimations of D.N.A. correlate well with the semiquantitative determinations by fluorescent microscopy (Bürgi et al., 1966; Bruce and Kumar, 1967). The D.N.A. fibres are located extracellularly in inflammatory secretions, in sharp contrast to their absence in sterile secretions, despite the occasional presence of large numbers of eosinophils. The D.N.A. concentration in sterile samples may reach $2.95 \mathrm{mg} . / \mathrm{ml}$. of sputum (mean of five samples $1.3 \mathrm{mg} . / \mathrm{ml}$. of sputum), and probably arises from intracellular D.N.A. which is liberated by the extraction procedure.

The L.D.H. activity in bronchial secretions originates either from blood plasma or from mucosal or inflammatory cells. It is therefore not surprising to find that the total L.D.H. may be very high in patients with severe destructive inflammatory changes in the bronchi, and low in sterile secretions in which smaller amounts of cellular elements, mostly of the mucosal type, are usually encountered. 
During antibiotic treatment the first observation is a change in L.D.H. activity, followed about one day later by a change in D.N.A. concentration. This may indicate an initial inhibition of disintegration of cellular elements in the sputum as the first effect of the antibiotic, followed later by a reduction in the absolute number of its cellular elements as a result of successful long-term therapy.

The determination of L.D.H. activity has proved to be a valuable method of estimating the efficacy of antibiotic therapy in the treatment of infection in patients with chronic bronchitis. In the case of bacterial resistance developing during antibiotic therapy a rise in L.D.H. activity will occur before clinical deterioration, and thus allow time for a change to other appropriate treatment. The separation of L.D.H. isoenzymes was performed to establish the origin of L.D.H. in bronchial secretions. It seems unlikely that L.D.H. is of bacterial origin, since the electrophoretic migration pattern of its fractions is identical with that of human serum. In uninfected bronchial secretions the L.D.H. isoenzymes resemble those found in normal serum, and it is possible that in this case they originate from that source. However, in infected sputum with a high L.D.H. activity the pattern of L.D.H. isoenzymes corresponds to that of leucocytes and probably mucosal cells.

\section{Summary}

Determination of lactic dehydrogenase activity (L.D.H.) in bronchial secretions is a simple method of differentiating between infected and uninfected chronic bronchitics. The values obtained correlate well with the results of the quantitative determination of deoxyribonucleic acid (D.N.A.) in the secretions. The D.N.A. content of sputum can easily be estimated semiquantitatively by fluorescent microscopy, and the results obtained by this method compare well with quantitative D.N.A. estimations.

We thank Dr. R. A. Bruce, consultant physician to the Wharfedale General Hospital, Otley, Yorkshire, for his help with the translation and proof-reading.

REFERENCES

Bruce, R. A., and Kumar, V. (1967). Lab. Pract., 16, 316. Bürgi, H., Regli, J., and Medici, T. (1965). Méd. et Hyg. (Genève), 23, 1169.

Bürgi, H., Regli, J., and Wiesmann, U. (1966). Lancet, 2, 111.

Medici, T., and Bürgi, H. (1965). Schweiz. med. W schr., 95, 1679.

Rawlins, $H$ (1953). Lancet, $2,538$.

Volkin, E. In W. E' (1954). Meth biochem. Anal., 1, 287

Wiems. R. (1959). Studies on Agar Gel Electrophoresis. Brussels.

\title{
Renal Involvement in Human Leptospirosis
}

\author{
VISITH SITPRIJA,* M.D., PH.D.
}

Brit. med. F. 1968, 2, 656-658

Renal involvement is common in leptospirosis. Azotaemia and proteinuria with abnormal urinary sediment are frequently noted. While definite pathological changes of acute tubular necrosis and interstitial nephritis have been described (Gsell, 1952, Areán, 1962), it has been stated that temporary azotaemia and oliguria may occur in the absence of significant renal damage (Edwards, 1959). Clinical improvement after intravenous fluid administration, along with the increase in urinary output, suggests that azotaemia is secondary to deficiency in volume. In one report the decreased renal function was mentioned (Cora, 1956). The glomerular filtration rate was markedly reduced, and the excretion of para-aminohippurate (P.A.H.) was almost negligible. Because of the discrepancy in the clinical data this investigation was undertaken to clarify the clinical patterns of renal function disturbances encountered in leptospirosis.

\section{Materials and Methods}

A study was made of 10 patients aged from 24 to 63 years, with leptospirosis proved by haemoculture or serology, whose blood urea nitrogen was over $40 \mathrm{mg} . / 100 \mathrm{ml}$. Eight were males and two were females. In all cases the causative micro-organisms were Leptospira bataviae. They were admitted to hospital on the fifth to the seventh day of illness. Immediately after admission the blood volume was measured by the summation method with both ${ }^{131} \mathrm{I}$-labelled albumin and ${ }^{51} \mathrm{Cr}$-tagged red blood cells (Moore et al., 1963). Endogenous creatinine and P.A.H. clearances were ascertained by the standard technique (Smith, 1956) before antibiotic therapy. Blood chemistry, including blood urea nitrogen (B.U.N.), serum creatinine, electrolytes, and osmolality, was determined every other day until

- Senior Lecturer in Medicine, Chulalongkorn Hospital Medical School, Bangkok, Thailand. the return to normal. Urinalysis was performed at two-day intervals until no abnormal finding was noted. Twenty-fourhour urine was collected on alternate days for determination of urea nitrogen, creatinine, sodium, and osmolality.

\section{Results}

Clinical Observations. - Body temperature ranged from 37.3 to $39.2^{\circ} \mathrm{C}$., and usually subsided three to four days after penicillin administration. All patients had stable vital signs. Jaundice was present in five patients whose total bilirubin varied from 5 to $24 \mathrm{mg} . / 100 \mathrm{ml}$. The liver-function test showed only a minimal degree of parenchymal hepatic damage. The patients are classified into two groups according to the serum creatinine. Group 1 comprises five patients with levels above $2 \mathrm{mg} . / 100$ $\mathrm{ml}$; the other five (group 2) had levels below $2 \mathrm{mg} . / 100 \mathrm{ml}$. The pertinent clinical data are shown in Table $\mathbf{I}$.

Blood Chemistry.-Serum sodium and potassium were within normal limits. Six patients had a $\mathrm{CO}_{2}$ content below 20 $\mathrm{mEq} / 1$, probably indicating metabolic acidosis. Five of these patients were in group 1. The average B.U.N. and creatinine in group 1 were 105.2 and $4.9 \mathrm{mg} . / 100 \mathrm{ml}$. respectively, in contrast with the values of 54.2 and $1.6 \mathrm{mg}$. in group 2 (Table I). The association between jaundice and impaired renal function was striking in group 1 , and this might reflect the more severe form of infection. The elevated B.U.N. and creatinine returned to normal within 7 to 10 days in group 1 and within 24 to 48 hours in group 2.

Urinary Output and Sediment.-The urine volume on the first hospital day ranged from 180 to $890 \mathrm{ml} . / 24$ hours, with an average of $485 \mathrm{ml}$., in group 1 . There was only a slight increase in urine flow after fluid load during the clearance study. In group 2 the urinary output varied from 235 to $700 \mathrm{ml} . / 24$ hours, with a mean of $463 \mathrm{ml}$. (Table I). After 